\title{
Distribution of $\mathrm{Pd}$ clusters on ultrathin, epitaxial $\mathrm{TiO}_{x}$ films on $\mathrm{Pt}_{3} \mathrm{Ti}(111)$
}

\author{
Christian Breinlich ${ }^{1}$, Maria Buchholz ${ }^{1,2}$, Marco Moors ${ }^{* 1,3}$, Tobias Pertram ${ }^{1}$, \\ Conrad Becker ${ }^{1,4}$ and Klaus Wandelt ${ }^{1,5}$
}

\author{
Full Research Paper \\ Address: \\ ${ }^{1}$ Institute of Physical and Theoretical Chemistry, University of Bonn, \\ Wegelerstraße 12, D-53115 Bonn, Germany, ${ }^{2}$ Institute of Functional \\ Interfaces, Karlsruhe Institute of Technology, D-76021 Karlsruhe, \\ Germany, ${ }^{3}$ Peter Grünberg Institute, Forschungszentrum Jülich, \\ Wilhelm-Johnen-Straße, D-52425 Jülich, Germany, ${ }^{4}$ Aix Marseille \\ Université, CNRS, CINaM UMR 7325, 13288 Marseille, France and \\ 5 Institute of Experimental Physics, University of Wroclaw, PI. Maksa \\ Borna, 50-204 Wroclaw, Poland

\section{Email:} \\ Marco Moors* -m.moors@fz-juelich.de \\ * Corresponding author \\ Keywords: \\ cluster growth; palladium; platinum-titanium alloy; scanning tunnelling \\ microscopy (STM); template; titanium oxide
}

Beilstein J. Nanotechnol. 2015, 6, 2007-2014. doi:10.3762/bjnano.6.204

Received: 01 June 2015

Accepted: 22 September 2015

Published: 09 October 2015

This article is part of the Thematic Series "Advanced atomic force microscopy techniques IV".

Guest Editor: T. Glatzel

(C) 2015 Breinlich et al; licensee Beilstein-Institut. License and terms: see end of document.

\begin{abstract}
Scanning tunnelling microscopy (STM) was used to investigate the nucleation and growth of palladium clusters on two different, ultrathin, epitaxial, titania films grown on $\mathrm{Pt}_{3} \mathrm{Ti}(111)$ surface. The first oxide phase, $\mathrm{z}^{\prime}-\mathrm{TiO}_{x}$, is anisotropic and consists of parallel stripes separated by trenches. Defects (i.e., oxygen vacancies) in this structure are confined to these trenches and act as nucleation sites. Therefore, the Pd clusters are mostly arranged in unidirectional rows along the trenches, creating a template effect. The second phase, $\mathrm{w}^{\prime}-\mathrm{TiO}_{x}$, exhibits a hexagonal, long range, $(7 \times 7) \mathrm{R} 21.8^{\circ}$, Moiré-type superstructure with fewer and shallower defects, making the template effect less discernible.
\end{abstract}

\section{Introduction}

Catalysts often consist of metal nanoparticles dispersed on an oxide support structure. Small metal particles on an insulating substrate exhibit different electronic properties than the corresponding bulk metal phase. Moreover, in many cases, the oxide surface not only acts as a support structure but also takes part in the reaction cycle, for example, in oxygen spillover to the metal particles $[1,2]$. Thus, the investigation of the properties of supported metal clusters and the influence of the metal-oxide interfaces are of great interest. In particular, titanium oxides are often correlated with the so-called strong metal support interaction (SMSI) effect, which describes the influence of a transition metal oxide support on noble metal clusters yielding novel catalytic properties [1-7]. In order to understand this effect, well-defined model systems are needed. "Well-defined" 
refers to both the clusters and the supporting substrate, as exemplified in [8-10] for example. In the ideal case, the clusters should be monodisperse or have at least a known size distribution. Ideal oxide surfaces can be favourably implemented in the form of thin epitaxial films. Such films grown on a single crystalline, metal support have several advantages: (a) standard surface science techniques can be applied due to the high conductivity of these films compared to the respective bulk oxides, (b) the films can be prepared with a very high degree of structural preciseness, and (c) the influence of bulk effects such as subsurface oxygen vacancies is excluded.

In this sense we concentrate here on the preparation of uniform Pd clusters on two different, ultrathin, epitaxial $\mathrm{TiO}_{x}$ films grown on a chemically ordered, $\mathrm{Pt}_{3} \mathrm{Ti}(111)$, single crystal surface. One of the $\mathrm{TiO}_{x}$ films has a rectangular structure and the other a hexagonal structure. In a recent publication we described the detailed protocol on how to grow these $\mathrm{TiO}_{x}$ films by direct oxidation of the $\mathrm{Pt}_{3} \mathrm{Ti}(111)$ surface at elevated temperatures [6]. Granozzi et al., who found very similar phases by "reactive evaporation" of titanium onto a $\mathrm{Pt}(111)$ surface in oxygen [7], introduced the notation $\mathrm{z}^{\prime}-\mathrm{TiO}_{x}$ (zigzag-like) for the rectangular and $\mathrm{w}^{\prime}-\mathrm{TiO}_{x}$ (wagon-wheel-like) for the hexagonal oxide phase, according to their appearance in STM images. Due to the similarity of our films to those described for Pt(111), we decided to simply adopt the same nomenclature throughout this paper. The rectangular $z^{\prime}-\mathrm{TiO}_{x}$ phase obtained on the $\mathrm{Pt}_{3} \mathrm{Ti}(111)$ surface exhibits characteristic stripes of densely packed, Ti-O rows of bilayer thickness. These are separated $1.44 \mathrm{~nm}$ apart from each other with parallel trenches in between. The w'- $\mathrm{TiO}_{x}$ phase consists of a hexagonal, oxygen-terminated, Ti-O bilayer, which shows similarities to the Moiré superstructure of ultrathin aluminium oxide films grown on the chemically ordered, $\mathrm{Ni}_{3} \mathrm{Al}(111)$ surface [11-14]. The advantages of growing an oxide film from a component of an ordered alloy surface with a higher enthalpy of oxide formation are the somewhat better structural quality of the resulting films and their improved reproducibility compared to films grown by "reactive evaporation" [7].

Both the $\mathrm{z}^{\prime}-\mathrm{TiO}_{x}$ phase on $\mathrm{Pt}(111)$ and the Moire superstructure of the alumina film on $\mathrm{Ni}_{3} \mathrm{Al}(111)$ have already been proven to be excellent templates for the ordered growth of metal clusters. Granozzi et al. found ordered rows of $\mathrm{Fe}$ and Au clusters along the trenches of the $\mathrm{z}^{\prime}-\mathrm{TiO}_{x}$ phase $[15,16]$, while other studies (also of our own group) demonstrated the growth of ordered arrays of, for example, Pd-, Au-, and Fe- [11-14] or Co-clusters on $\mathrm{Al}_{2} \mathrm{O}_{3} / \mathrm{Ni}_{3} \mathrm{Al}(111)$ [10]. In the present paper we investigate the template effect of two different structures of the same type of oxide on the cluster growth of the same metal, namely Pd on $\mathrm{z}^{\prime}-\mathrm{TiO}_{x}$ and $\mathrm{w}^{\prime}-\mathrm{TiO}_{x}$.

\section{Experimental setup}

The scanning tunnelling microscopy (STM) experiments were conducted on our custom-built LT-STM, which for the experiments presented in this paper, was run at room temperature. The sample was prepared in an adjacent preparation chamber, which was equipped with a sputter gun, low energy electron diffraction (LEED) optics and an Auger electron spectroscopy (AES) analyser. The STM tips were electrochemically etched from a $0.5 \mathrm{~mm}$ tungsten wire and cleaned under ultra-high vacuum (UHV) conditions using voltage pulses of $10 \mathrm{~ms}$ duration between -10 and $+10 \mathrm{~V}$. The STM data were analysed with the WSxM freeware program [17].

The (111)-oriented $\mathrm{Pt}_{3}$ Ti crystal was purchased from MaTeck (Jülich, Germany) and cleaned using several cycles of argon sputtering at $900 \mathrm{~K}$ for $10 \mathrm{~min}$ with subsequent annealing at $1100 \mathrm{~K}$ for another $10 \mathrm{~min}$ in order to restore the surface structure. The crystallographic and chemical order of the surface was verified by a sharp $(2 \times 2)$ superstructure visible in LEED experiments and the absence of any carbon or oxygen contamination in AES experiments.

Palladium was evaporated from a simple Knudsen cell with a slow deposition rate of approximately $2 \cdot 10^{-3} \mathrm{MLs}^{-1}$. The amount deposited was controlled by the deposition time and monitored by the evolution of the $330 \mathrm{eV}$ Pd AES signal in relation to the $505 \mathrm{eV}$ oxygen signal, as well as by the number density and size of the metal clusters seen in the STM images. The surface was kept at room temperature during evaporation and no post-deposition annealing was carried out.

\section{Results and Discussion \\ The rectangular z'-TiO ${ }_{x}$ (zig-zag-like) phase}

Exposing the clean $\mathrm{Pt}_{3} \mathrm{Ti}(111)$ surface to rather small amounts of oxygen gas (less than $200 \mathrm{~L}$ dosed in the $10^{-8}$ mbar range) at temperatures between 800 and $1100 \mathrm{~K}$ results in the formation of the $\mathrm{z}^{\prime}-\mathrm{TiO}_{x}$ phase [6]. This atomically thin, titanium oxide phase is characterized by a typical striped pattern in the STM images. Former LEED measurements have shown a commensurate rectangular unit cell with a $(6 \times 3 \sqrt{ } 3)$ superstructure with respect to the $(1 \times 1)$ spots of the alloy surface and a unit cell size of $(16.6 \pm 0.2) \times(14.4 \pm 0.2) \AA$, while high resolution electron energy loss spectroscopy (HREELS) and X-ray photoelectron spectroscopy (XPS) measurements indicated the existence of an oxygen-terminated Ti-O bilayer [6,7]. Depending on the applied oxygen dose, the $\mathrm{z}^{\prime}-\mathrm{TiO}_{x}$ phase covers different fractions of the crystal surface, ranging from small separated islands up to a nearly complete film covering the whole surface. Figure 1a,b shows STM images of such an ultrathin oxide film, which was prepared by dosing $45 \mathrm{~L}$ of oxygen while holding the sample temperature at $1000 \mathrm{~K}$. This amount of oxygen was 


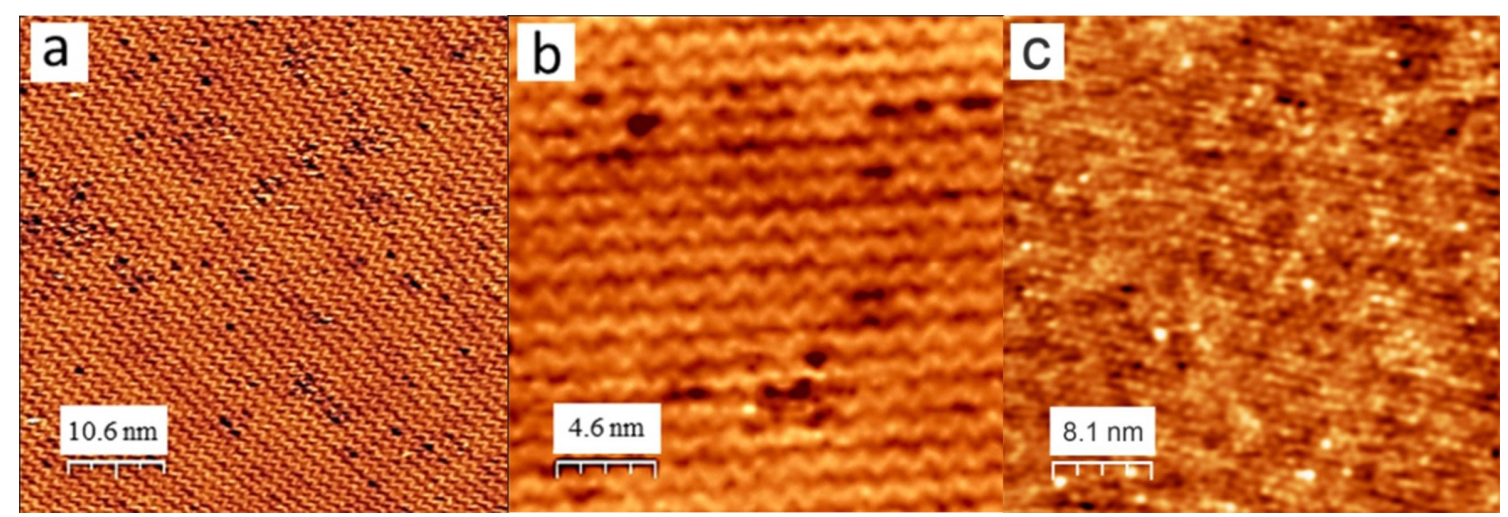

Figure 1: STM image of the $z^{\prime}-T_{i O}$ phase: (a) $53.3 \times 53.3 \mathrm{~nm}^{2}$, bias voltage $U_{\mathrm{B}}=0.91 \mathrm{~V}, I_{T}=50 \mathrm{pA}$, (b) $22.8 \times 22.8 \mathrm{~nm}^{2}, U_{\mathrm{B}}=0.99 \mathrm{~V}, I_{T}=40 \mathrm{pA}$, and (c) STM image of the $\mathrm{w}^{\prime}-\mathrm{TiO}_{x}$ phase $\left(57.1 \times 57.1 \mathrm{~nm}^{2}, U_{\mathrm{B}}=-1.08 \mathrm{~V}, I_{T}=55 \mathrm{pA}\right)$. The images in (a) and (c) have been adapted with permission from [6], copyright 2014 American Chemical Society.

sufficient to cover more than $80 \%$ of the alloy surface with $\mathrm{Z}^{\prime}-\mathrm{TiO}_{x}$. The stripes, which are approximately $1.4 \mathrm{~nm}$ apart from each other and separated by darker trenches, show the characteristic zigzag motif after which this structure was named. Inside the bright stripes the density of titanium atoms is higher than in the trenches, which is a result of the lattice mismatch between the titanium oxide film and the metallic substrate.

As suggested by theoretical calculations, the stripes consist of titanium atoms of different coordination [18]. Using a negative tip potential, four-fold oxygen-coordinated Ti atoms appear with the highest contrast in the STM images. They are surrounded by less bright, three-fold oxygen-coordinated $\mathrm{Ti}$ atoms. This mixture of Ti atoms of different electronic density is responsible for the characteristic striped pattern of the $\mathrm{z}^{\prime}-\mathrm{TiO}_{x}$ phase [18]. The STM images in Figure 1a,b also show several defects with the appearance of small black holes and a rough depth of $40 \mathrm{pm}$, which are all located within the trenches. At these point defects, titanium and oxygen atoms are probably missing and, thus, the bare metallic substrate is exposed [7] Growth experiments with $\mathrm{Au}$ and $\mathrm{Fe}$ have already shown that both the trenches and, in particular, these defect sites within the trenches are preferred nucleation sites for cluster growth $[15,16]$.

\section{Pd cluster growth on the $z^{\prime}-\mathrm{TiO}_{x}$ phase}

Figure 2a shows an STM image of a $z^{\prime}-\mathrm{TiO}_{x}$ surface onto which Pd was deposited at room temperature for $90 \mathrm{~s}$ $(\approx 0.1 \pm 0.05 \mathrm{ML})$. The stripes and trenches of the $\mathrm{z}^{\prime}-\mathrm{TiO}_{x}$ structure are visible in Figure 2a running from the upper left to the lower right of the image. In the close-up Figure 2b, the direction and separation of the trenches are accentuated by parallel lines. The individual Pd clusters are nearly all located within the trenches between the stripes. Only a few larger elongated clus- ters are visible. The tilted orientation of their long axis with respect to the trench orientation may be suggestive of two coalesced clusters at adjacent defects in two neighbouring stripes. They are not equally spaced within the trenches and appear more or less randomly distributed along the trenches. Most of the clusters are imaged larger than the width of the trenches, but their centres are always within the trenches. The distribution of the cluster diameters and cluster heights as taken from Figure 2a are displayed in Figure 2c,d and show a mean diameter of $3.5 \pm 1.6 \mathrm{~nm}$ and a height of 1.5-2 A. It should be noted, however, that the measured particle diameter is actually the result of a convolution between the true particle size and the STM tip shape [14]. The actual particle diameter is smaller, but the distribution obtained for different coverages and the two different substrates still allow for comparison. Regarding the measured heights of 1.5-2 $\AA$, it must be considered that this may not be the true geometric height due to electronic effects. However, it is safe to assume that the Pd particles are only one layer thick. These results are in good agreement with the published results of Au clusters grown on the corresponding $\mathrm{Z}^{\prime}-\mathrm{TiO}_{x}$ phase on $\mathrm{Pt}(111)$ [15].

The observed arrangement of the clusters is a consequence of the diffusion behaviour of the deposited metal atoms on this structurally anisotropic oxide surface. On the one hand the palladium-oxygen interaction is not very strong, permitting metal atom mobility at room temperature [19]. On the other hand, the trenches (1D depressions) guide the Pd atom diffusion preferentially along the grooves. Such anisotropic diffusion behaviour has been observed in the inverse system, namely the oxidation of $\operatorname{Pd}(110)$ leading to the growth of pronounced, elongated, oxide islands [20]. Thus, in the initial phase of the cluster growth, two competing processes take place: The defects, which are distributed randomly within (and only 

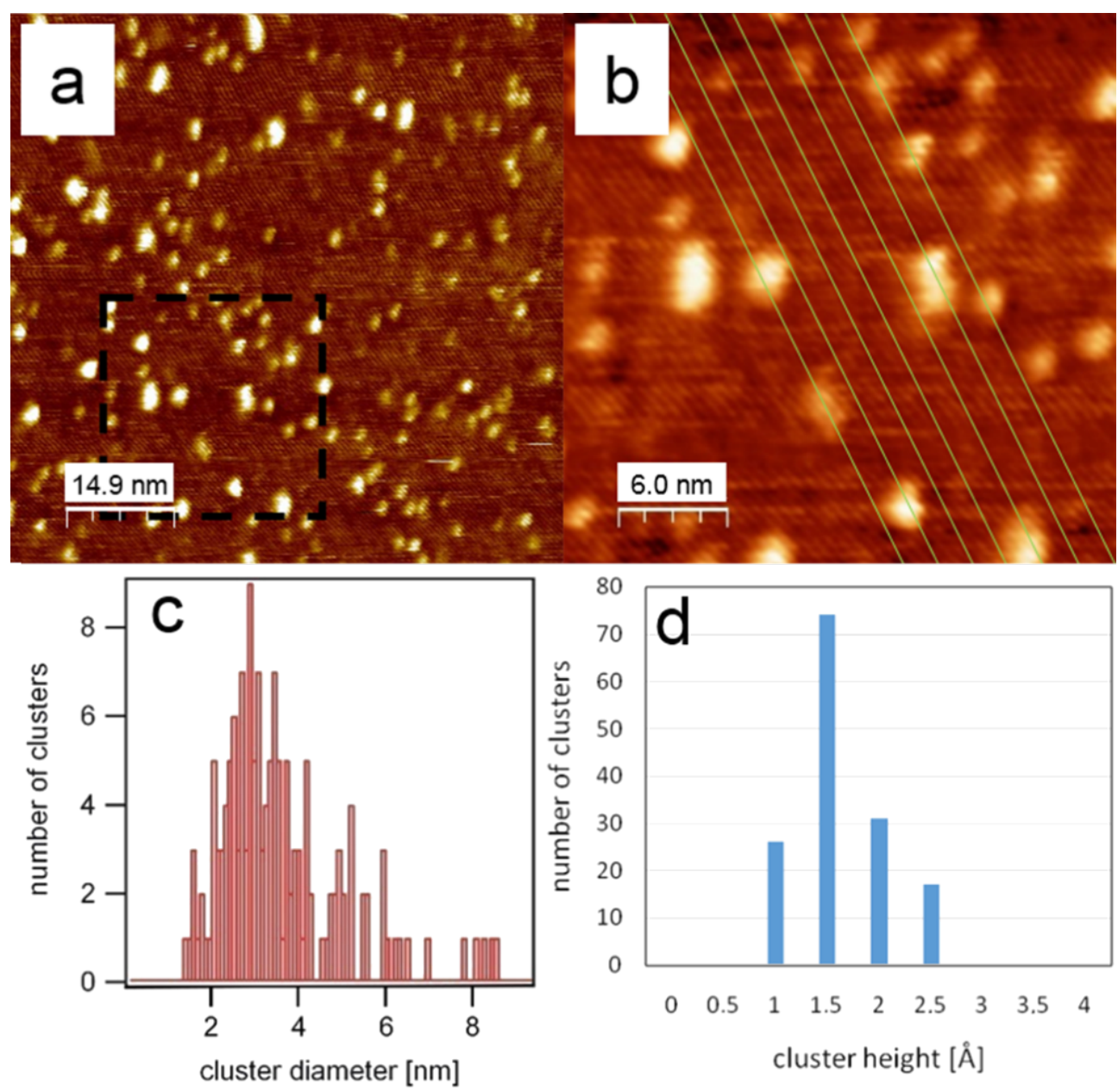

Figure 2: (a) STM image of $\mathrm{Pd}$ clusters grown at room temperature on a $\mathrm{z}^{\prime}-\mathrm{TiO}_{x}$ covered surface with a $\mathrm{Pd}$ coverage of $0.1 \pm 0.05 \mathrm{ML}$ after $90 \mathrm{~s}$ of $\mathrm{Pd}$ deposition $\left(76.1 \times 76.1 \mathrm{~nm}^{2}, U_{\mathrm{B}}=0.8 \mathrm{~V}, I_{\mathrm{T}}=56 \mathrm{pA}\right)$, (b) detailed view for the marked section from image (a), (c) corresponding size distribution and (d) height distribution of $\mathrm{Pd}$ clusters. The green lines in (b) mark the trenches of the $\mathrm{z}^{\prime}-\mathrm{TiO}_{x}$ substrate.

within) the trenches, will trap some Pd atoms and thereby act as heterogeneous nucleation sites. In principle, homogeneous nucleation may also occur at other places within the trenches when two or three diffusing Pd atoms meet and form an immobile nucleus. However, in the case of low coverage as studied here, heterogeneous nucleation dominates. Counting the number of visible defects in typical images of the $\mathrm{z}^{\prime}-\mathrm{TiO}_{x}$ phase such as in Figure 1a leads to a typical defect density of approximately $3.9 \cdot 10^{4}$ defects per $\mu \mathrm{m}^{2}$. Comparing this value with a typical cluster density of $3.7 \cdot 10^{4}$ clusters per $\mu \mathrm{m}^{2}$ (calculated by counting the Pd clusters in Figure 2a) supports our observation that the cluster formation on the surface is directly related to the defects along the trenches of the $\mathrm{z}^{\prime}-\mathrm{TiO}_{x}$ phase.

The result is an anisotropic template effect of the $\mathrm{z}^{\prime}-\mathrm{TiO}_{x}$ phase: The clusters are arranged in lines along the trenches, but not equally spaced within the trenches or across the stripes in neighbouring trenches.

\section{The hexagonal $\mathrm{w}^{\prime}-\mathrm{TiO}_{x}$ (wagon-wheel-like) phase}

The $\mathrm{w}^{\prime}-\mathrm{TiO}_{x}$ phase is the second stable titanium oxide phase that can be grown on the $\mathrm{Pt}_{3} \mathrm{Ti}(111)$ surface with oxygen doses higher than $200 \mathrm{~L}$ within a temperature window of 800-1100 K [6]. HREELS and XPS studies also indicated a Ti-O bilayer structure with oxygen termination as a basic structure element for this phase [6,7]. LEED measurements revealed a hexagonal, higher-order commensurate $(7 \times 7) \mathrm{R} 21.8^{\circ}$ superstructure with unit cell lattice vectors of $19.4 \pm 0.2 \AA$. In contrast to the $\mathrm{z}^{\prime}-\mathrm{TiO}_{x}$ phase, however, it always covers the entire surface. This can be seen as the crucial factor for the symmetry change. At complete surface coverage, it is energetically more favourable for the oxide film to adopt the hexagonal symmetry of the substrate. This is normally not very common for titanium oxides and makes the $\mathrm{w}^{\prime}-\mathrm{TiO}_{x}$ phase a very interesting object of investigation. For the experiments presented here, the oxide film was prepared by exposing the sample to a temperature of 
$1000 \mathrm{~K}$ with $400 \mathrm{~L}$ of oxygen at a pressure of $1 \cdot 10^{-7}$ mbar. The STM image in Figure 1c shows a hexagonal arrangement of bright protrusions with nearly the same lattice parameters as measured by LEED [6]. This structure can be interpreted as a Moiré pattern that arises from the coincidence of the lattices of the metal support and the oxide overlayer. A Moiré pattern with a $(7 \times 7) \mathrm{R} 21.8^{\circ}$ superstructure can be created by superimposing a hexagonal oxide layer with a unit cell size of $3.18 \AA$ on the metal substrate with a unit cell size of $2.76 \AA$, rotated by $3.5^{\circ}$ [7]. Those positions where the oxygen atoms are situated on top or on bridge sites of the metal substrate lattice are imaged brighter in the STM when using a negative tip potential. The number density of defects that exhibit an apparent depth of $18 \mathrm{pm}$ is significantly lower than on the $\mathrm{z}^{\prime}-\mathrm{TiO}_{x}$ surface, as visualized later in Figure 5b,d.

\section{$\mathrm{Pd}$ cluster growth on the $\mathrm{w}^{\prime}-\mathrm{TiO}_{x}$ phase}

Figure 3 shows two STM images obtained at comparatively low $(\approx 0.15 \mathrm{ML}$, Figure $3 \mathrm{a})$ and high $(\approx 0.75 \mathrm{ML}$, Figure $3 \mathrm{~b}) \mathrm{Pd}$ coverages on the $\mathrm{w}^{\prime}-\mathrm{TiO}_{x}$ surface obtained after $90 \mathrm{~s}$ and $420 \mathrm{~s}$ of deposition, respectively.
The clusters are imaged as bright spots with an almost circular shape on the oxide surface (see Figure 4a,b). For the lower coverage (Figure 3a and Figure 4a), the clusters appear to be distributed randomly on the surface and have an apparent height between 1.5 and $3 \AA$, as indicated by the height distribution in Figure $4 \mathrm{c}$. This height corresponds to a single layer of $\mathrm{Pd}$. The imaged mean diameter of a cluster is $1.9 \pm 0.7 \mathrm{~nm}$, as shown in the histogram in Figure 3c. At the higher coverage (Figure $3 \mathrm{~b}$ and Figure 4b), the apparent height of the clusters increased to about 6-8 $\AA$. This value suggests that the clusters are now 1 to 4 Pd layers thick and thus indicates that $3 \mathrm{D}$ growth has started. The imaged mean diameter increased to $5.5 \mathrm{~nm}$ with a broader size distribution of $\pm 2.9 \mathrm{~nm}$ (Figure $3 \mathrm{~d}$ ).

From the energetic point of view, a precondition for 3D growth (i.e., nonwetting), is that the adhesion energy of the Pd metal on the oxide is smaller than twice the surface free energy of the vacuum-metal interface of the liquid metal [19]. In the case of late transition metals on oxides, this criterion is usually met, and thus $3 \mathrm{D}$ growth is observed in most cases [14]. From a kinetic point of view, the growth process can be divided into two
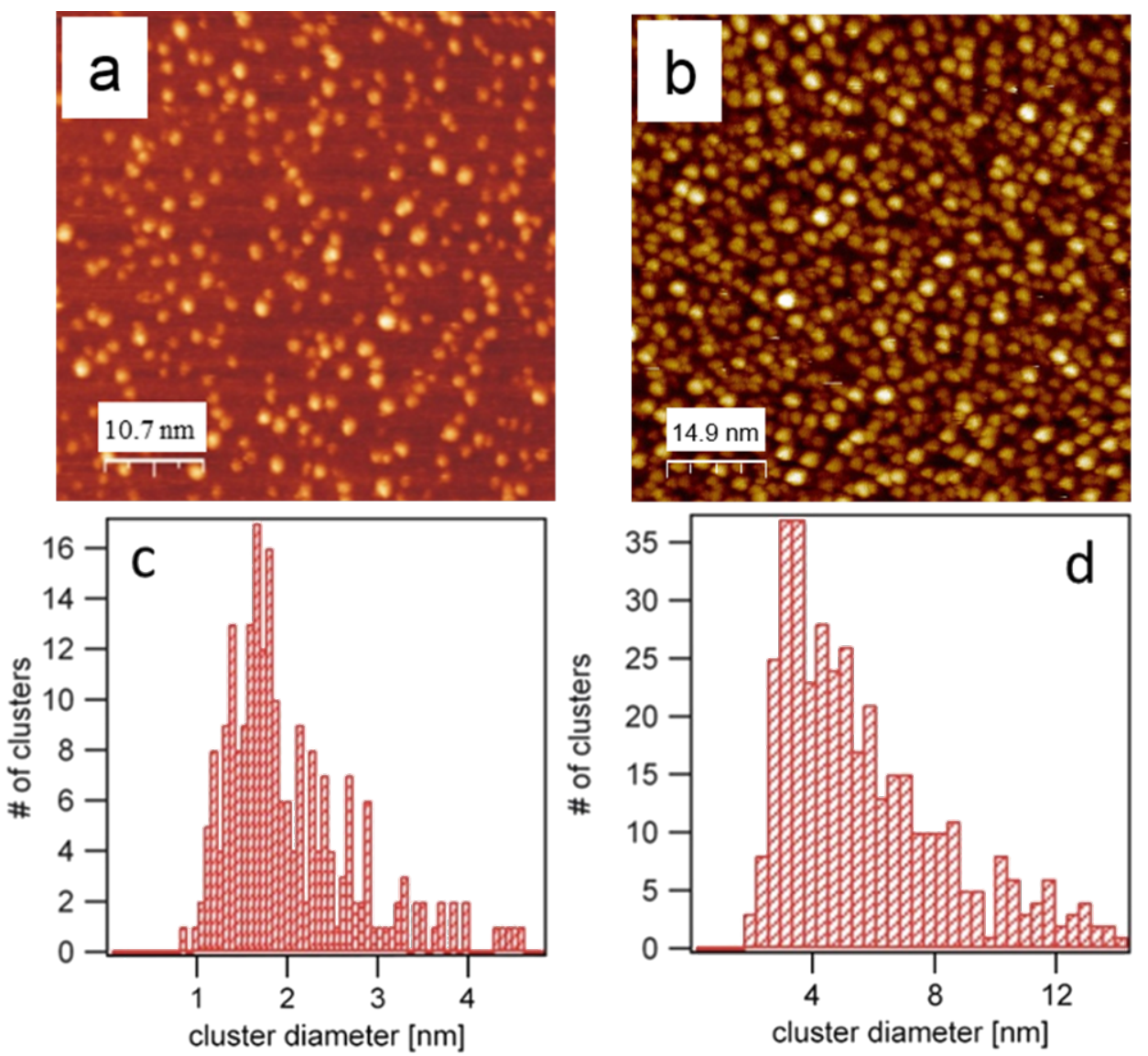

Figure 3: Pd clusters grown at RT on the $\mathrm{w}^{\prime}-\mathrm{TiO}_{x}$ phase: (a) low Pd coverage of $0.15 \pm 0.02 \mathrm{ML}$ after $90 \mathrm{~s}$ of $\mathrm{Pd}$ deposition $\left(53.3 \times 53.3 \mathrm{~nm}{ }^{2}\right.$, $\left.U_{\mathrm{B}}=0.9 \mathrm{~V}, I_{\mathrm{T}}=53 \mathrm{pA}\right)$, (b) high Pd coverage of $0.73 \pm 0.05 \mathrm{ML}$ after $420 \mathrm{~s}$ of Pd deposition $\left(76.1 \times 76.1 \mathrm{~nm}^{2}, U_{\mathrm{B}}=2.13 \mathrm{~V}, I_{\mathrm{T}}=57 \mathrm{pA},(\mathrm{c})\right.$ size distribution of the cluster from (a), and (d) size distribution of the clusters from (b). 

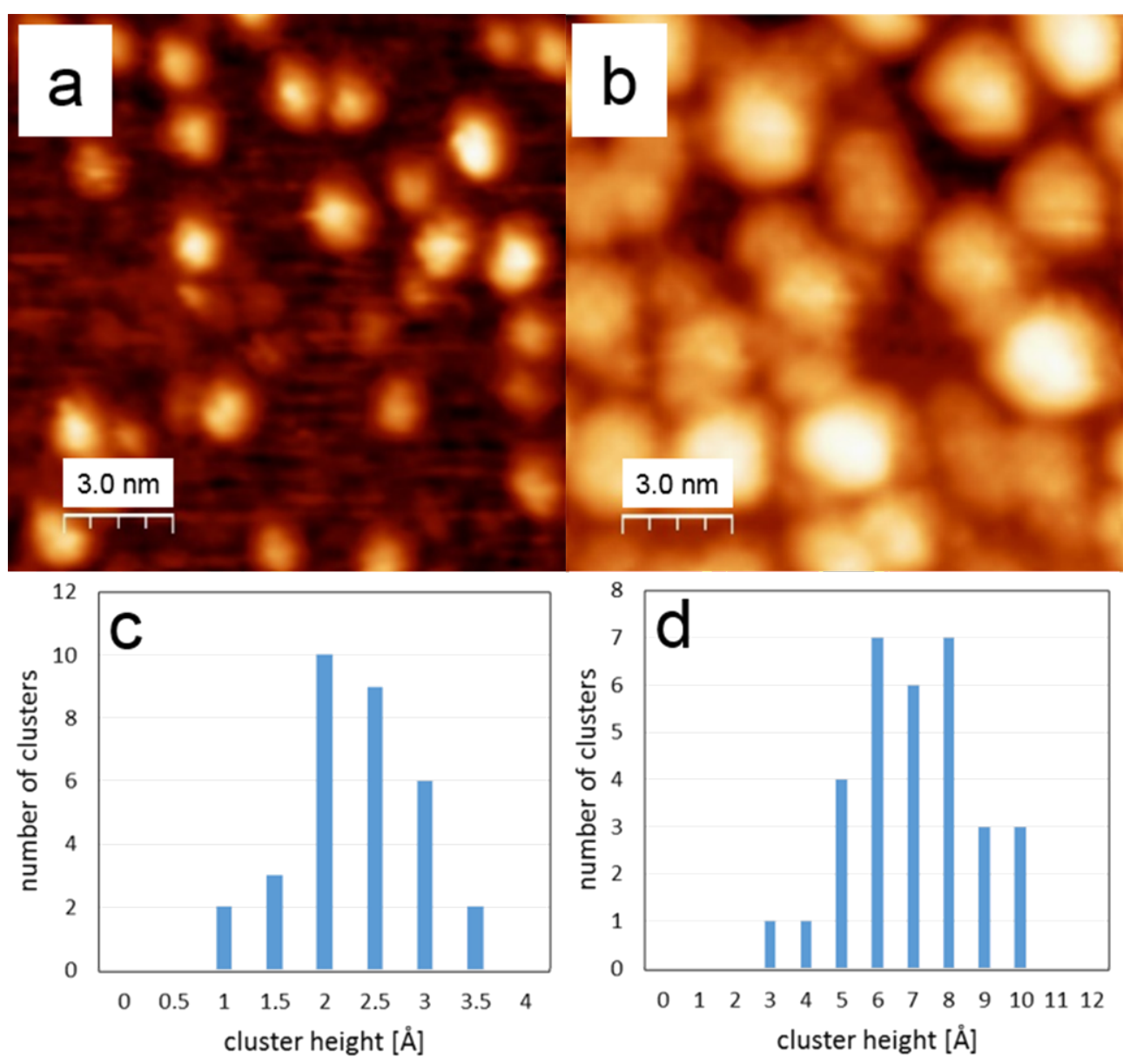

Figure 4: Enlarged STM images of Pd clusters on the w'-TiO $x$ phase: (a) with the low coverage, indicating a height of one layer (2-3 $\AA$ ), (b) with the high coverage, indicating a height of up to four layers $(9-10 \AA),(c)$ and (d) show the cluster height distributions from (a) and (b), respectively.

regimes: In the case of homogeneous nucleation, deposited metal atoms diffuse across a low corrugation surface and randomly combine to form stable nuclei at random positions on the surface until a saturation density is reached; then these nuclei grow in size during the further deposition process. Heterogeneous nucleation occurs on a surface of higher corrugation on which the diffusing atoms are trapped at the sites of highest adsorption energy, which thereby become preferred nucleation and growth sites. Obviously, defect sites are such traps. As shown in Figure 5a, defects in the $\mathrm{z}^{\prime}-\mathrm{TiO}_{x}$ phase (depth $\approx 40 \mathrm{pm}$ ) are largely found within the trenches as an inherent property of this phase. As a consequence, the $\mathrm{z}^{\prime}-\mathrm{TiO}_{x}$ phase exerts a "template effect": The trenches are the defect locations, which in turn are the preferred nucleation sites for the Pd clusters. In turn, as shown in Figure 5 b, the $\mathrm{w}^{\prime}-\mathrm{TiO}_{x}$ phase contains much fewer and shallower (depth $\approx 18 \mathrm{pm}$ ) defects of no particular distribution. Therefore, under the given experimental conditions, it does not exert a noticeable "template effect".
This result is quite in contrast to Pd cluster growth on $\mathrm{Al}_{2} \mathrm{O}_{3}$ / $\mathrm{Ni}_{3} \mathrm{Al}(111)$ surfaces, where actually two different hexagonal superstructures with lattice constants of $2.4 \mathrm{~nm}$ and $4.1 \mathrm{~nm}$ act as templates for the growth of ordered metal cluster arrays [14]. A hexagonal arrangement of more equally sized clusters on the $\mathrm{w}^{\prime}-\mathrm{TiO}_{x}$ Moiré structure, which is even more ideal than described in this work, is certainly achievable. This could be accomplished by varying the impact rate of $\mathrm{Pd}$ atoms and their mobility on the surface (i.e., the deposition rate and the substrate temperature), as was the case for Pd cluster growth on the $\mathrm{Al}_{2} \mathrm{O}_{3} / \mathrm{Ni}_{3} \mathrm{Al}(111)$ surface.

\section{Summary}

$\mathrm{Pd}$ clusters were grown on two different, ultrathin, $\mathrm{TiO}_{x}$ films, the so-called rectangular $\mathrm{z}^{\prime}-\mathrm{TiO}_{x}$ and the hexagonal $\mathrm{w}^{\prime}-\mathrm{TiO}_{x}$ phase. The first one consists of stripes separated by trenches and acts as a unidirectional template. This is due to the defect sites, which act as heterogeneous nucleation sites for the Pd clusters. These are an inherent property of the $\mathrm{z}^{\prime}-\mathrm{TiO}_{x}$ phase and 

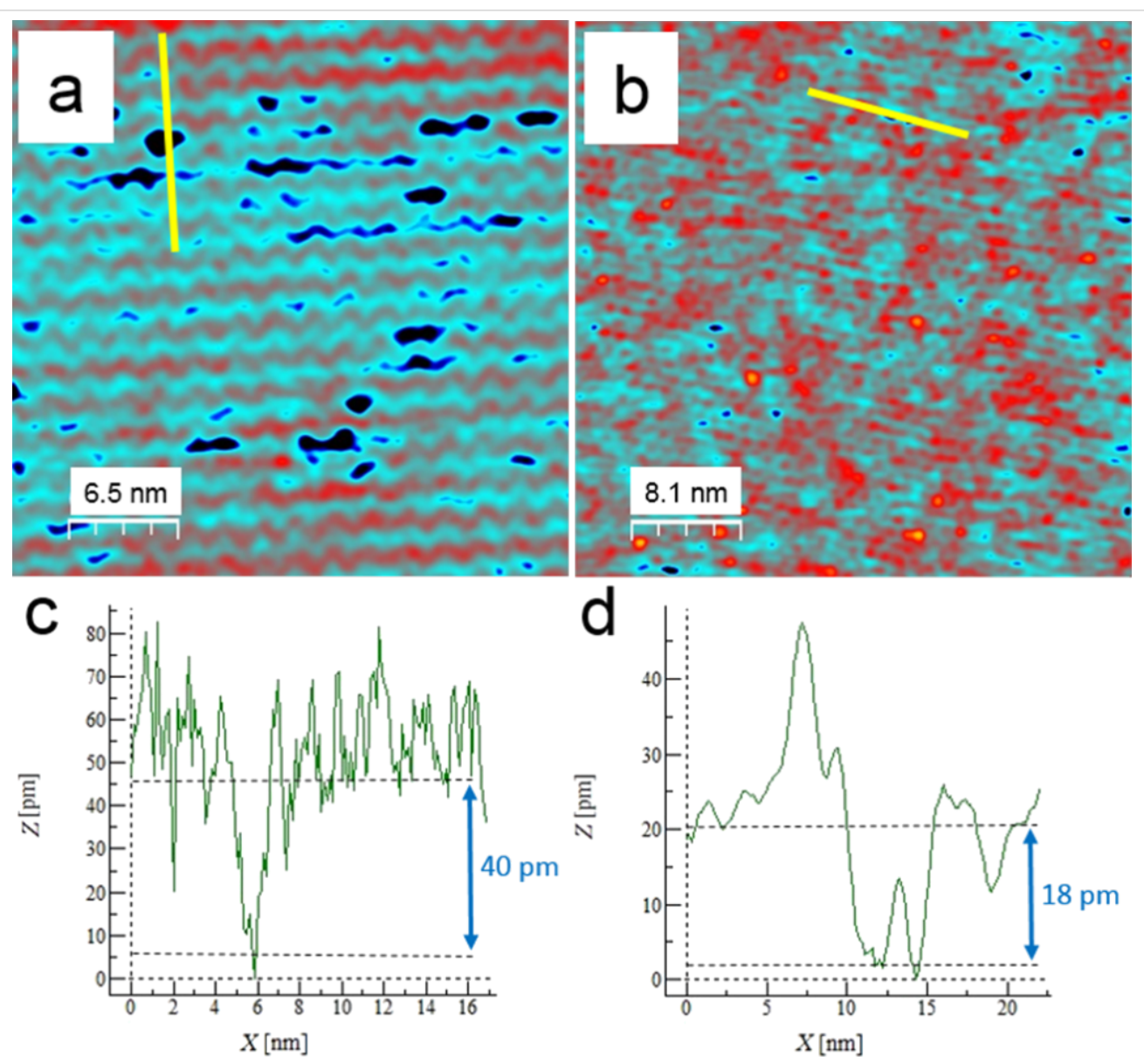

Figure 5: STM images of the oxide films: (a) $\mathrm{z}^{\prime}-\mathrm{TiO}_{x}$ phase $\left(32.6 \times 32.6 \mathrm{~nm}^{2}\right.$, bias voltage $U_{\mathrm{B}}=0.97 \mathrm{~V}, I_{\mathrm{T}}=50 \mathrm{pA}$, (b) $\mathrm{w}^{\prime}-\mathrm{TiO}_{x}$ phase $\left(57.1 \times 57.1 \mathrm{~nm}^{2}, U_{\mathrm{B}}=-1.08 \mathrm{~V}, I_{\mathrm{T}}=55 \mathrm{pA}\right),(\mathrm{c})$ and (d) corresponding line profiles along the markings in image (a) and (b), respectively. Image (b) has been adapted with permission from [6], copyright 2014 American Chemical Society.

are aligned within the trenches of this structure. Along the trenches, no long-range order of the defects, and hence of the clusters, is discernible.

The $\mathrm{w}^{\prime}-\mathrm{TiO}_{x}$ phase possesses a long-range $(7 \times 7) \mathrm{R} 21.8^{\circ}$ superstructure, which is formed as a Moiré pattern from the superposition of the hexagonal lattices of the substrate and the oxide film. Since this structure exhibits much fewer (and shallower) defects, no "template effects" could be observed for this surface and this type of metallic cluster under the given experimental conditions.

The next reasonable steps would be (a) to attempt to achieve a hexagonal cluster distribution on the $\mathrm{w}^{\prime}-\mathrm{TiO}_{x}$ phase by varying the metal deposition rate and/or the substrate temperature as was the case for metal clusters on $\mathrm{Al}_{2} \mathrm{O}_{3} / \mathrm{Ni}_{3} \mathrm{Al}(111)$, and (b) the investigation of the electronic as well as the adsorption and reactivity properties of the Pd clusters. In this regard, the influence of the two different titania films on these properties of clusters of the same metal is of particular interest [21].

\section{References}

1. Dulub, O.; Hebenstreit, W.; Diebold, U. Phys. Rev. Lett. 2000, 84, 3646. doi:10.1103/PhysRevLett.84.3646

2. Bowker, M.; Stone, P.; Morrall, P.; Smith, R.; Bennett, R.; Perkins, N.; Kvon, R.; Pang, C.; Fourre, E.; Hall, M. J. Catal. 2005, 234, 172. doi:10.1016/j.jcat.2005.05.024

3. Tauster, S. J.; Fung, S. C.; Garten, R. L. J. Am. Chem. Soc. 1978, 100, 170. doi:10.1021/ja00469a029

4. Resaco, D. E.; Haller, G. L. J. Catal. 1983, 82, 279 doi:10.1016/0021-9517(83)90194-X

5. Santos, J.; Phillips, J.; Dumesic, J. A. J. Catal. 1983, 81, 147. doi:10.1016/0021-9517(83)90154-9

6. Breinlich, C.; Buchholz, M.; Moors, M.; Le Moal, S.; Becker, C.; Wandelt, K. J. Phys. Chem. C 2014, 118, 6186. doi:10.1021/jp4105213

7. Sedona, F.; Rizzi, G. A.; Agnoli, S.; Labrès i Xamena, F. X.; Papageorgiou, A.; Ostermann, D.; Sambi, M.; Finetti, P.; Schierbaum, K.; Granozzi, G. J. Phys. Chem. B 2005, 109, 24411. doi:10.1021/jp0543173

8. N'Diaye, A. T.; Gerber, T.; Busse, C.; Mysliveček, J.; Coraux, J.; Michely, T. New J. Phys. 2009, 11, 103045. doi:10.1088/1367-2630/11/10/103045 
9. Venkataramani, K.; Helveg, S.; Hunnemann, B.; Reichling, M.; Besenbacher, F.; Lauritsen, J. V. Nanotechnology 2010, 21, 265602. doi:10.1088/0957-4484/21/26/265602

10. Chaudhury, A.; Gragnaniello, L.; Ma, T.; Surnev, S.; Netzer, F. P. J. Phys. Chem. C 2013, 117, 18112. doi:10.1021/jp4056329

11. Degen, S.; Becker, C.; Wandelt, K. Faraday Discuss. 2004, 125, 343. doi:10.1039/b303244b

12. Becker, C.; von Bergmann, K.; Rosenhahn, A.; Schneider, J.; Wandelt, K. Surf. Sci. 2001, 486, L443. doi:10.1016/S0039-6028(01)01052-4

13. Lehnert, A.; Krupski, A.; Degen, S.; Franke, K.; Decker, R.; Rusponi, S.; Kralj, M.; Becker, C.; Brune, H.; Wandelt, K. Surf. Sci. 2006, 600, 1804. doi:10.1016/j.susc.2006.02.013

14. Becker, C.; Wandelt, K. Scanning Tunneling Microscopy in Surface Science; Wiley-VCH: Weinheim, Germany, 2010.

15. Sedona, F.; Agnoli, S.; Fanetti, M.; Kholmanov, I.; Cavaliere, E.; Gavioli, L.; Granozzi, G. J. Phys. Chem. C 2007, 111, 8024. doi:10.1021/jp0687652

16. Cavaliere, E.; Kholmanov, I.; Gavioli, L.; Sedona, F.; Agnoli, S.; Granozzi, G.; Barcaro, G.; Fortunelli, A. Phys. Chem. Chem. Phys. 2009, 11, 11305. doi:10.1039/b915641k

17. Horcas, I.; Fernández, R.; Gómez-Rodríguez, J. M.; Colchero, J.; Gómez-Herrero, J.; Baro, A. M. Rev. Sci. Instrum. 2007, 78, 013705. doi:10.1063/1.2432410

18. Sedona, F.; Granozzi, G.; Barcaro, G.; Fortunelli, A. Phys. Rev. B 2008, 77, 115417. doi:10.1103/PhysRevB.77.115417

19. Campbell, C. T. Surf. Sci. Rep. 1997, 27, 1. doi:10.1016/S0167-5729(96)00011-8

20. Kralj, M.; Pertram, T.; Seriani, N.; Mittendorfer, F.; Krupski, A.; Becker, C.; Wandelt, K. Surf. Sci. 2008, 602, 3706. doi:10.1016/j.susc.2008.10.008

21. The authors were no longer in the position to do these experiments because of the retirement of the group leader (K.W.) and the closure of the laboratories.

\section{License and Terms}

This is an Open Access article under the terms of the Creative Commons Attribution License (http://creativecommons.org/licenses/by/2.0), which permits unrestricted use, distribution, and reproduction in any medium, provided the original work is properly cited.

The license is subject to the Beilstein Journal of Nanotechnology terms and conditions: (http://www.beilstein-journals.org/bjnano)

The definitive version of this article is the electronic one which can be found at: doi:10.3762/bjnano.6.204 